\begin{tabular}{lcl}
\hline Bentham OPEN & The Open Ophthalmology Journal & $\begin{array}{l}\bar{T} \text { The Open } \\
\text { Ophthalmology } \\
\text { lournal }\end{array}$ \\
\hline CrossMark & Content list available at: www.benthamopen.com/TOOPHTJ/ & DOI: $10.2174 / 1874364101610010027$ \\
\hline
\end{tabular}

\title{
A Case of Anterior Chamber Cholesterolosis Due to Coats' Disease and a Review of Reported Cases
}

\author{
Andrew W. Stacey ${ }^{1, *}$, Melissa Borri ${ }^{2}$, Sonia De Francesco ${ }^{2}$, Angela S. Antenore ${ }^{2}$, Felice Menicacci ${ }^{2}$ \\ and Theodora Hadjistilianou ${ }^{2}$ \\ ${ }^{1}$ Department of Ophthalmology and Visual Sciences, University of Michigan, Ann Arbor, Michigan, USA \\ ${ }^{2}$ Unit of Ophthalmology, University of Siena, Policlinico "Santa Maria alle Scotte" Siena, Italy
}

\begin{abstract}
:
Purpose:

To present the case of an 18 month old boy with Coats' disease who was found to have anterior chamber cholesterolosis.

Methods:

Case presentation and review of reported cases.

Results:

An 18 month old boy presented with unilateral stage 3B Coats' disease without other clinical findings. Two weeks after presentation he returned with xanthocoria due to anterior chamber cholesterolosis. He subsequently developed hyphema, neovascular glaucoma, and was enucleated. His case is compared to all previously reported cases of Coats' disease leading to anterior chamber cholesterolosis.
\end{abstract}

\section{Conclusion:}

The presentation of anterior chamber cholesterolosis in Coats' disease can range from the incidental finding in an asymptomatic patient to acute angle closure glaucoma with pain and acutely decreased vision. Clinicians should be aware of this potential complication of Coats' disease as it denotes a poor visual prognosis.

Keywords: Cholesterolosis, coats' disease, prognosis, anterior chamber.

\section{INTRODUCTION}

The presence of cholesterol crystals in the vitreous cavity, known as synchysis scintillans or cholesterolosis bulbi, is a rare condition first described in 1828 by Parfait-Landrau [1]. The most common etiologies of cholesterolosis bulbi include ocular trauma and degenerative ocular disease. Rarely, the cholesterol crystals can migrate into the anterior chamber, a finding first described by Schmidt in 1831 [2]. A comprehensive review of all reported cases of anterior chamber cholesterolosis bulbi was published by Eagle et al. in 1975 [3]. They evaluated 88 reported cases of anterior chamber cholesterolosis and found that more than $70 \%$ of cases occurred after ocular trauma. They also found that nearly two-thirds of cases had no light perception (NLP) vision while more than $90 \%$ of cases had only light perception (LP) vision or worse.

Coats' disease is an ocular condition characterized by retinal telangiectasias, intra-retinal and subretinal exudation.

\footnotetext{
* Address correspondence to this author at the Department of Ophthalmology and Visual Sciences, University of Michigan 1000 Wall Street Ann Arbor, MI 48103, USA; Tel: 614-598-3420; E-mail: astacey@med.umich.edu
} 
In advanced Coats' disease, vascular leakage can lead to exudative retinal detachments, neovascular glaucoma, blindness, and enucleation [4]. While exudation and cholesterol formation are common in Coats' disease, these findings are usually confined to the subretinal space. The first case of anterior chamber cholesterolosis secondary to Coats' disease was reported by Shields et al. in 1995 [5]. Gupta et al. reported a second case in 2009 [6] and the Shields' group recently published a photo essay illustrating a third case of anterior chamber cholesterolosis in Coats' disease [7]. Further, in a review of 150 consecutive patients with Coats' disease, Shields et al. noted anterior chamber cholesterol crystals in 4 patients (2-3\% of all eyes) [8]. Herein we report another case of anterior chamber cholesterolosis in a child with Coats' disease and review the previously published reports.

\section{CASE REPORT}

An 18 month old boy presented to our ocular oncology referral center with the diagnosis of leukocoria in the left eye. He had no other past medical or past ocular history and family history was negative for retinoblastoma. Upon initial examination, there was no light perception (NLP) vision in the left eye. The patient was able to fix and follow normally with the right eye. Intraocular pressures were within normal limits in both eyes. Ocular examination was normal in the right eye. In the left eye, the retina was visible on external examination through the pupil (Fig. 1). Fundus exam through the pupil revealed a total, exudative, retinal detachment with diffuse retinal telangiectasias, leading to a diagnosis of Coats' disease. Given the stage of the disease and poor prognosis, the family agreed to defer treatment and chose comfort care only for the left eye.

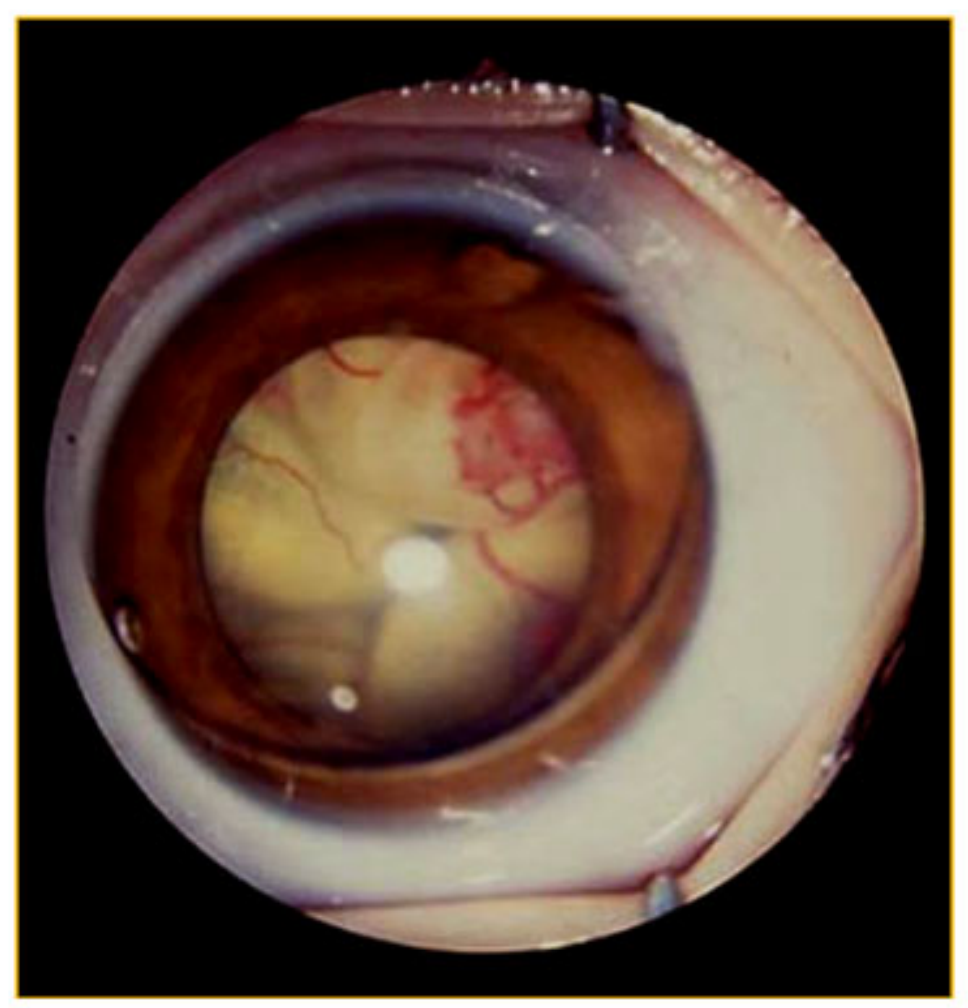

Fig. (1). External examination of the left eye at initial presentation. A total retinal detachment is visible through the pupil along with diffuse retinal telangiectasias.

Two weeks after his initial presentation, the child returned to the hospital with a red, painful, left eye. His family denied any other changes systemically. External ophthalmic examination at this time revealed conjunctival injection and xanthocoria (yellow pupil), both new findings (Fig. 2). Slit lamp examination revealed an anterior chamber occupied by a turbid, yellow, proteinaceous fluid. The material was reflective and filled the entire anterior chamber, completely obscuring any view to the pupil or the posterior segment. These findings were consistent with an interval development of anterior chamber cholesterolosis. The intraocular pressure at this time was $52 \mathrm{mmHg}$. There was no view to the posterior segment due to the anterior segment opacity. B-scan ultrasonography revealed no masses or calcifications but did corroborate his previous retinal exam by showing massive subretinal exudation (Fig. 3). 
The patient returned one week later for follow up exam. In that week the right eye had developed a complete hyphema with continued evidence of anterior chamber cholesterol (Fig. 4). The intraocular pressure in the right eye was still $45 \mathrm{mmHg}$. The patient's exam findings at this time, including glaucoma, hyphema, and anterior chamber cholesterolosis, were consistent with Stage 5 Coats' disease [4]. Due to pain, NLP vision, and inability to examine the posterior segment, the eye was enucleated. Pathologic examination of the enucleated globe confirmed the diagnosis of Coats' disease with evidence of thickened and dilated capillaries as well as intraretinal and subretinal exudation (Fig. 5). His course has been uneventful since enucleation.

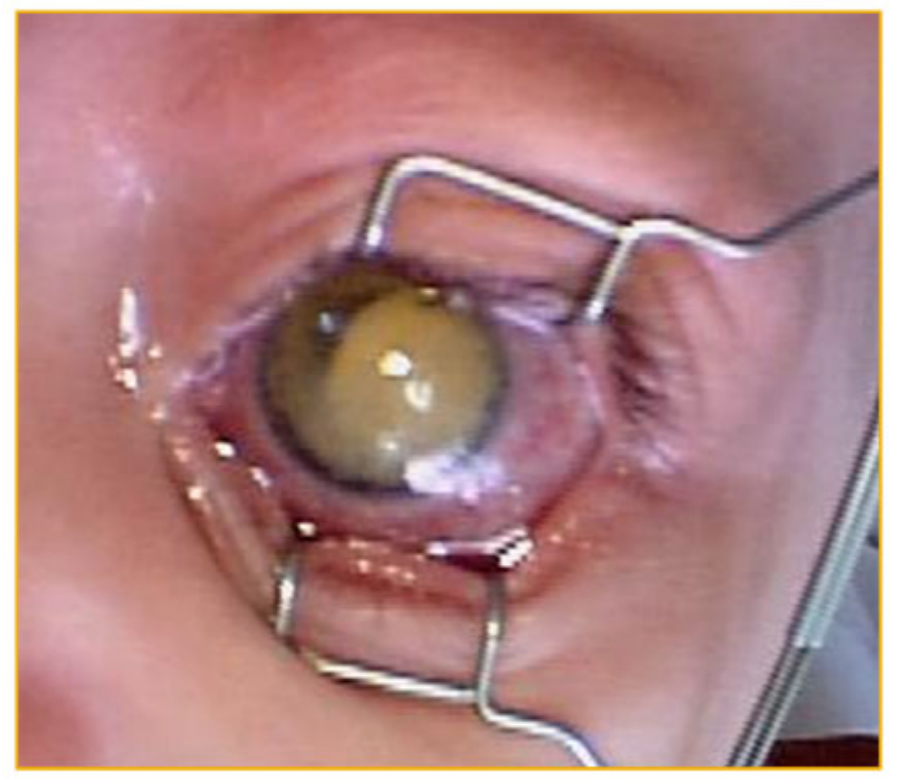

Fig. (2). External exam two weeks after initial presentation. New exam findings noted at this time included conjunctival injection and xanthocoria.

Including this case, there are four specific reports of anterior chamber cholesterol in patients with Coats' disease. The characteristics of these four patients are outlined in Table 1. All four patients are male. One other patient presented in an acute pain crisis as our patient did, while in the other two patients the cholesterol was noted incidentally.

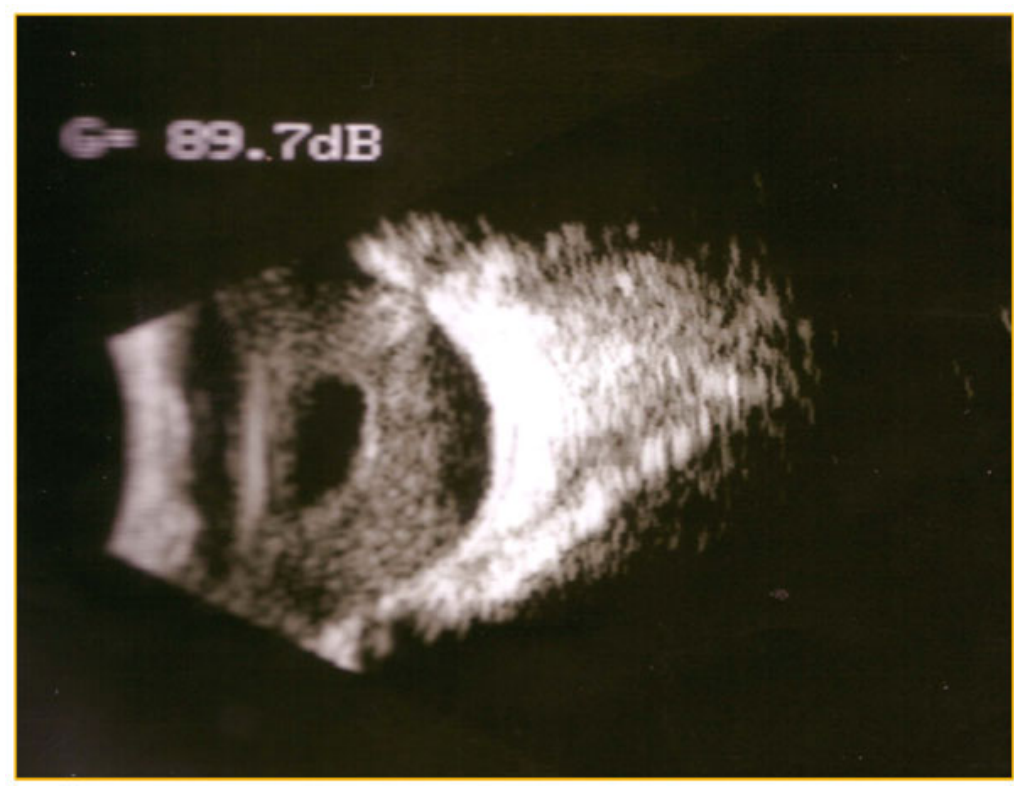

Fig. (3). B-scan ultrasonography obtained when patient returned with anterior chamber opacification. The image reveals massive subretinal exudation and retinal detachment expected with advanced Coats' disease. 
Three patients had no light perception vision while the other had bare light perception vision. Interestingly, all four patients carried a diagnosis of Coats' disease prior to the development of anterior chamber cholesterolosis. All four eyes were enucleated.

\section{DISCUSSION}

Cholesterolosis bulbi (synchysis scintillans) is an uncommon finding in general, and is thought to be due to hemorrhage, trauma, or chronic inflammation. Anterior chamber cholesterolosis is rare, and its pathogenesis not well understood. It has been suggested that cholesterol crystals can enter the anterior chamber either de novo following hyphema or through passages from the posterior segment [3] usually secondary to trauma. In the cases of anterior chamber cholesterolosis in Coats' disease reported in Table 1, there was no hyphema present and no history of trauma in any patient at the time of diagnosis. We agree with previous authors, therefore, that anterior chamber cholesterol in patients with Coats' disease is likely a result of anteriorly displaced cholesterol from the posterior segment [5, 6]. For this to occur, there would need to be structural alterations in the retina, first allowing crystals to migrate into the vitreous space, and also in the lens/zonular complex, allowing crystals to enter the posterior and anterior chambers. It has been suggested that chronic retinal detachments, a finding in many patients with Coats' disease, may allow crystals to pass through the retina [9]. Furthermore, chronic inflammation and zonular abnormalities, also potential findings in patients with Coats' disease and chronic detachments, have been implicated in the passage of cholesterol from the vitreous to the anterior chamber [3]. We suspect this is the route for anterior chamber cholesterol in patients with Coats' disease.

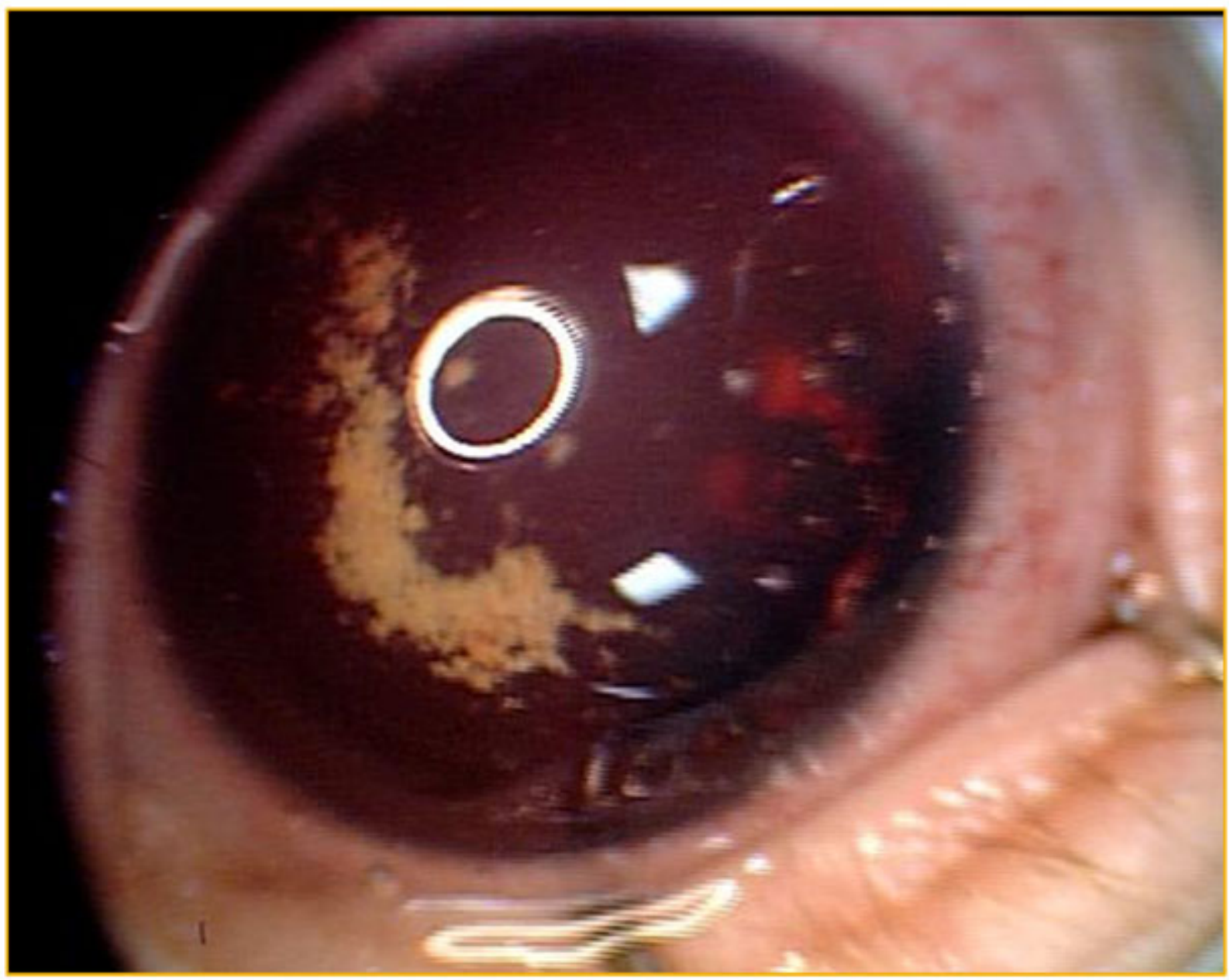

Fig. (4). Follow-up external examination of the left eye revealed the development of a total hyphema and a few residual cholesterol crystals. 

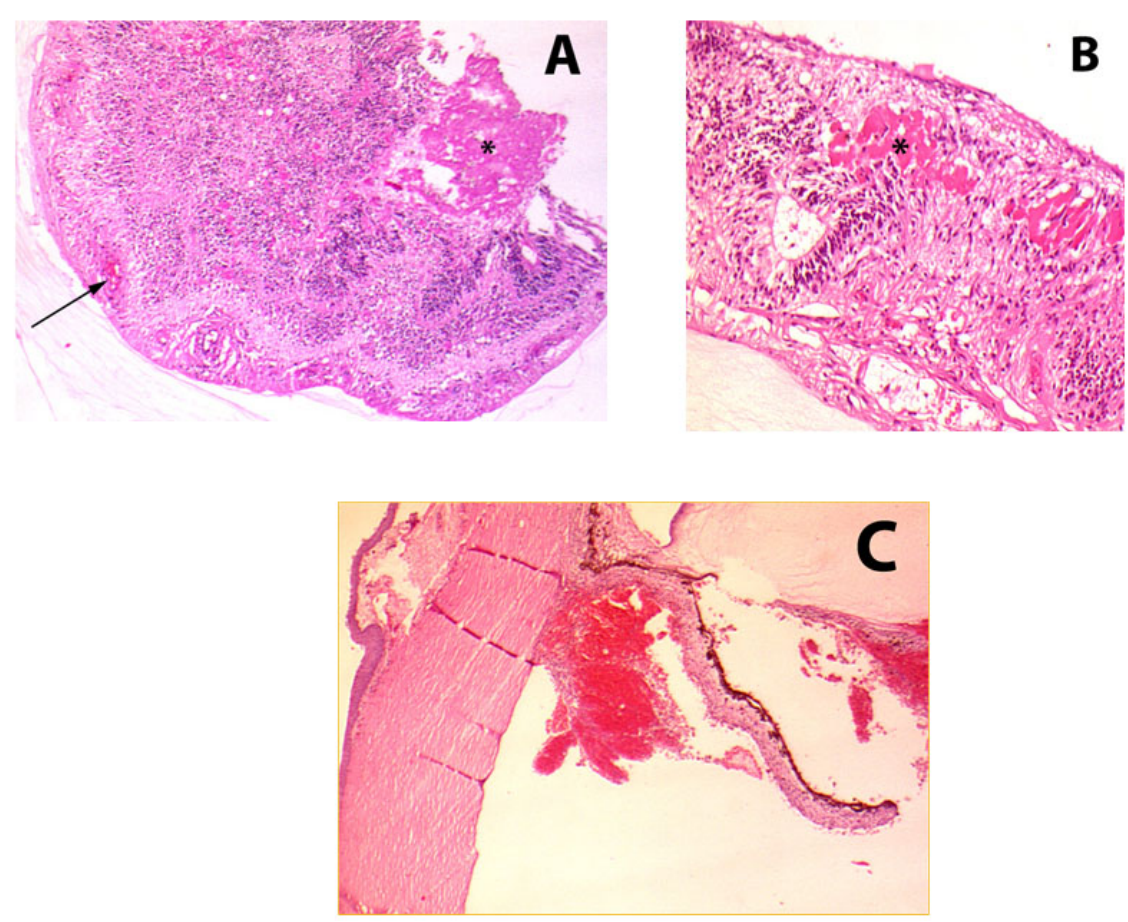

Fig. (5). (A) Low magnification view of thickened retina with diffuse inflammation, dilated capillaries (arrow), and subretinal exudation (asterisk). (B) Higher magnification view of intraretinal exudates (asterisk). (C) View of anterior segment and angle where there is evidence of blood in the anterior chamber, the posterior chamber, and the angle structures.

The development of anterior chamber cholesterolosis is a rare complication of Coats' disease, reported in less than $3 \%$ of patients [8]. The visual prognosis of these eyes is uniformly dismal, with light perception vision or worse in all reported cases and $75 \%$ of reported cases with no light perception. These outcomes are similar to those reported for all causes of anterior chamber cholesterolsis [3]. There appear to be two subsets of patients who present with anterior chamber cholesterol in Coats' disease. In two of the patients described in Table 1 the crystals were noted during an acute glaucomatous pain crisis with intraocular pressures (IOP) of 33 and 52. However, the other two patients had normal to normal IOP and the crystals were noted incidentally.

Table 1. A review of the reported cases of anterior chamber cholesterolosis in Coats' disease. In addition to these cases, Sheilds et al. found that 4 out of 150 consecutive patients with Coats' disease had anterior chamber cholesterol [8]. However, the specifics of these cases we not reported.

\begin{tabular}{|c|c|c|c|c|c|c|c|c|c|}
\hline Patient & $\begin{array}{c}\text { Age at } \\
\text { presentation }\end{array}$ & Sex & $\begin{array}{l}\text { Stage of Coats' } \\
\text { disease } \\
\text { prior to } \\
\text { development of } \\
\text { cholesterolosis }\end{array}$ & $\begin{array}{c}\text { Time } \\
\text { between last } \\
\text { follow up and } \\
\text { development } \\
\text { of cholesterol }\end{array}$ & $\begin{array}{l}\text { Presenting } \\
\text { symptom }\end{array}$ & $\begin{array}{c}\text { Visual acuity } \\
\text { at } \\
\text { Presentation }\end{array}$ & $\underset{(\mathbf{m m H g})}{\text { IOP }}$ & Notes & Reference \\
\hline 1 & 1 year, 7 months & Male & $3 \mathrm{~B}$ & 4 months & Pain & NLP & 33 & & $\begin{array}{c}\text { Shields et al. } \\
{[5]}\end{array}$ \\
\hline 2 & 13 years & Male & $2 \mathrm{~B}$ & 12 years & $\begin{array}{c}\text { Xanthocoria } \\
\text { ("shinning } \\
\text { eye") }\end{array}$ & NLP & 5 & $\begin{array}{c}\text { Phthisis bulbi } \\
\text { with an axial } \\
\text { length of } \\
16 \mathrm{~mm} \text {, lens } \\
\text { was subluxed }\end{array}$ & $\begin{array}{c}\text { Gupta et al. } \\
\text { [6] }\end{array}$ \\
\hline 3 & $\begin{array}{l}2 \text { years, } 7 \\
\text { months }\end{array}$ & Male & $3 \mathrm{~B}$ & 5 months & $\begin{array}{c}\text { Incidental } \\
\text { finding during } \\
\text { follow-up }\end{array}$ & LP & 13 & $\begin{array}{c}\text { Developed } \\
\text { after } \\
\text { bevacizumab } \\
\text { injections }\end{array}$ & $\begin{array}{l}\text { Patel et al. } \\
\quad \text { [7] }\end{array}$ \\
\hline 4 & 1 year, 6 months & Male & $3 \mathrm{~B}$ & 2 weeks & Pain & NLP & 52 & $\begin{array}{c}\text { Subsequent } \\
\text { total hyphema }\end{array}$ & This report \\
\hline
\end{tabular}

Neovascular glaucoma is a common outcome in advanced Coats' disease, however the presence of cholesterol in the 
anterior chamber during the glaucoma crisis is unexpected. The remarkable finding in our patient is the speed at which a typical eye with Stage 3B Coats' disease developed a neovascular glaucoma crisis and concomitant anterior chamber cholesterol. The transformation was complete only two weeks after an otherwise unremarkable exam of a stage 3B eye. While anterior chamber cholesterol in Coats' disease does not appear to always be associated with angle closure glaucoma, this is the second reported case where the two entities occurred simultaneously. Those who treat patients with Coats' disease should recognize the risk of anterior chamber cholesterolosis and its accompanying poor prognosis.

\section{CONFLICT OF INTEREST}

The authors confirm that this article content has no conflict of interest.

\section{ACKNOWLEDGEMENTS}

Declared none.

\section{REFERENCES}

[1] Parfait-Landau M. Cas de pathologie relatif a des corpuscles de l'oeil, donnant lieu a des images fantastique. Rev Med 1828 ; 4 : 203.

[2] Schmidt J. Die Cataracta. Eine Abhandlung aus den hinterlassenen Papieren des Well. Z Ophthal 1831; $1: 382$.

[3] Eagle RC Jr, Yanoff M. Cholesterolosis of the anterior chamber. Albrecht Von Graefes Arch Für Klin Exp Ophthalmol Albrecht. Graefes Arch Clin Exp Ophthalmol 1975; 193: 121-34.

[http://dx.doi.org/10.1007/BF00419356]

[4] Shields JA, Shields CL, Honavar SG, Demirci H, Cater J. Classification and management of Coats disease: the 2000 Proctor Lecture. Am J Ophthalmol 2001; 131(5): 572-83. [http://dx.doi.org/10.1016/S0002-9394(01)00896-0] [PMID: 11336931]

[5] Shields JA, Eagle RC Jr, Fammartino J, Shields CL, De Potter P. Coats' disease as a cause of anterior chamber cholesterolosis. Arch Ophthalmol 1995; 113(8): 975-7.

[http://dx.doi.org/10.1001/archopht.1995.01100080025014] [PMID: 7639669]

[6] Gupta N, Beri S, D'souza P. Cholesterolosis bulbi of the anterior chamber in coats disease. J Pediatr Ophthalmol Strabismus 2009. [http://dx.doi.org/10.3928/01913913-20090616-04] [PMID: 19645389]

[7] Patel AK, Murphy M, Shields CL. Picture of the month: anterior chamber cholesterolosis in Coats disease. Arch Pediatr Adolesc Med 2011; 165(12): 1131-2.

[http://dx.doi.org/10.1001/archpediatrics.2011.190-a] [PMID: 22147780]

[8] Shields JA, Shields CL, Honavar SG, Demirci H. Clinical variations and complications of Coats disease in 150 cases: the 2000 Sanford Gifford Memorial Lecture. Am J Ophthalmol 2001; 131(5): 561-71. [http://dx.doi.org/10.1016/S0002-9394(00)00883-7] [PMID: 11336930]

[9] Sanmugasunderam S, Giligson A, Choi SB. A “sparkling” eye. CMAJ 2003; 169(4): 319. [PMID: 12925430]

Received: October 30, 2015 Revised: November 12, 2015 Accepted: November 15, 2015

(C) Stacey et al.; Licensee Bentham Open.

This is an open access article licensed under the terms of the Creative Commons Attribution-Non-Commercial 4.0 International Public License (CC BY-NC 4.0) (https://creativecommons.org/licenses/by-nc/4.0/legalcode), which permits unrestricted, non-commercial use, distribution and reproduction in any medium, provided the work is properly cited. 